\title{
Novice Teachers' Professional Development: A Meta-Analysis
}

\author{
Hasina Banu Shirin*, Abrar Yahya Khawaji \\ Doctor of Philosophy, International Islamic University, Malaysia
}

*Corresponding Author: Hasina Banu Shirin, Doctor of Philosophy, International Islamic University, Malaysia

\begin{abstract}
With the start of this new Millennium everything in this planet are changing rapidly. We as a social being are trying to up-to date, reform and modernize every single aspect. So, in this present era teachers are the paramount variables who need professional development. Novice teachers should know the processes of good teaching because these procedures may assist them to learn how to teach and how to be an excellent teacher.
\end{abstract}

Keywords: Assist, Professional Development, Novice Teachers, Excellent Teacher

\section{INTRODUCTION}

In this paper, some research articles on Novice Teachers' Professional development have been reviewed. All these articles are published as an international journal, models, case studies and so on. Calderhead and Shorrok (1997) claimed, "Knowing what' and 'knowing how' teachers must also be competent in 'knowing why' and 'knowing when". In other words, these methods can be defined as a long-term process. "The professional development of teacher is a life-long process which begins with the initial preparation that teachers receive (whether at an institute of teacher education or actually on the job) and contains until retirement" (Eleonora Villegas-Reimers, 2003).

\section{REVIEWED ARTICLES}

2.1. Jeffrey Barrett, Graham Jones, Edward Mooney, Carol Thornton, JoAnn Cady, Patricia Guinee and Jo Olson "Working with Novice Teachers: Challenges for Professional Development". (Illinois State, 2002).

The purpose of this study was to examine the beliefs and classroom practices of two novice teachers during the first year of PRIME and to know the dilemmas and challenges that arose for both the teachers and professional developers. The subject of this research was working with novice teachers. This case study included two novice teachers and the data were collected from four sources (1) Videotapes, (2) Detailed field notes of six teaching sessions, (3) Field notes of interviews associated with the six-teaching sessions and (4) Samples of students' work. From the findings of this study, it is observed that the classroom practice and beliefs of two novice teachers and the professional development experience which was problematic for different reasons to the different perspectives of the two novice teachers. According to Wesley (1999), "Working in isolation gives the novice a tunnel vision of effective practice and results in isolation and limited, if any, professional growth." Professional development effort is an important deliberation for Novice teachers.

\subsection{Cameron Montgomery \& André A. Rupp in "A Meta-analysis for Exploring the Diverse Causes and Effects of Stress in Teachers" (Canada, 2003).}

This study correlated 78 independent written and published studies on teachers' stress. It intended to measure the relationship between teachers' stress and numerous characteristics such as coping, burnout, emotional responses, personality mediators, personal support, environmental structure and background characteristics. $\mathrm{N}=2,527$ marginal effect size was used to estimate the empirical relationship between the operationalized theoretical constructs. Sampling frame and stages, the experimental design structure, the population(s) sampled, and the statistical methodologies were used for this research study. The findings provide an overview of teachers' stress as it found that emotional response, personality mediators support variables and burnout play a central role in the manner in which teachers respond to stressful situations. 


\subsection{Ulla Lindgren "Professional Support to Novice Teachers by Mentoring” (Sweden, 2004)}

Ulla Lindgren (Department of Swedish and Social Sciences, Umea University, Sweden) conducted a study regarding "Professional support to novice teachers by mentoring" in 2004. The criteria for participation in his study were that the participant was a recently graduated teacher who had as little experience of teaching as possible and was working with children in the ages 7-16 and had received a mentor. When the interviews of this study were carried out in 2004, the teachers had two years of teaching experience and the mentoring period had been one year previously. The aim with the interviews was to find out how the seven (07) novice teachers had experienced having a mentor one year after the mentoring program was ended. Four of the seven teachers' interviews were carried out by phone and three at the different schools of the teachers. The interviews were carried out in a calm and secluded environment without any interruptions by means of Telephone and face to face interview. Each interview took approximately 45 minutes. When the teachers were asked about the mentoring six of them remembered the discussions with the mentor as the most important. It was so good with these discussions, the possibilities to talk about one's work. The reflections were so good. Unfortunately, one of the teachers was disappointed about his own mentor and the result of the mentoring, mainly depending on the mentor's low engagement. As a result, they had become more aware of their professional practice, which indicates personal and professional growth. Most likely this awareness had influenced their attitudes and opinions about the teacher role and school work.

The above statements show how important it is for novice teachers to be able to discuss acute problems and frustrations that they have experienced while teaching with their mentors.

The advice to future colleagues to carefully put aside time for the mentor discussions and to prepare oneself for them, show that the teachers had experienced the mentoring positively and that they were able to see both the advantage of and the need for mentoring. Results shown by international studies concerning the importance of mentoring for beginner teacher's professional development (Mullen \& Kealy, 1999; Andrews \& Martin, 2003; Ganser, 2003) is to a great extent confirmed by the novice teachers in this study.

\subsection{Orna Fallik, Bat-Sheva Eylon, Sherman Rosenfeld "Motivating Teachers to Enact Free- Choice Project-Based Learning in Science and Technology (PBLSAT): Effects of a Professional Development Model” (New York, 2008)}

The study 'Motivating Teachers to Enact Free-Choice Project-Based Learning in Science and Technology (PBLSAT): Effects of a Professional Development Model' was conducted by Orna Fallik, Bat-Sheva Eylon, Sherman Rosenfeld in 2008. The purpose of their research was to study the effectiveness of CPD model for free-choice PBL (project-based learning) in Science and Technology from the perspective of the participating novice and expert PBLSAT teachers. They conducted two studies. The first one dealt with the first support framework with its novice teachers, while the second one dealt with the expert teachers, who participated in both frameworks.

In their first study, they addressed two research questions: 1 . How do novice teachers evaluate their knowledge of PBLSAT skills before and after the first support framework (PBLSAT workshop)? 2. What are the perceived benefits and difficulties of PBLSAT for students, teachers, and the school, according to the novice teachers?

Three groups of middle school science and technology teachers participated in the first support framework (The Teacher as Learner workshops). Group 1 studied during the summer of 2000 and included 20 novice teachers; the central subject was Transport Systems. Group 2 studied during the summer of 2001 and included 24 novice teachers; the central subject was Materials.

Group 3 studied during the summer of 2001 and included 21 novice teachers; the central subject was Senses and Sensors. In this workshop, the teachers engaged in the process of design and technological development, rather than in the process of scientific research. In total, 58 novice teachers completed questionnaires in the beginning and at the end of the workshops (seven teachers did not complete either the pre- or posttest and were dropped from the analysis). The study employed two parts of questionnaire: open-ended and close ended responses. The data show that the teachers in Group 1 felt they had acquired some of the PBLSAT skills, to some degree, before they began the workshop. Their self-evaluation of the same PBLSAT skills increased as a result of the workshop. 
The data of the second group, like the first group, show that teachers evaluated themselves as having acquired the PBLSAT skills to some degree, prior to the workshop. The skill that received the highest pre-workshop self-evaluation (inner line) was formulating a research question. PBLSAT skills that showed the lowest teachers' pre-workshop self-evaluation were writing a proposal, peer evaluation, developing evaluation criteria, and R\&D methods. Unlike the other two groups, the third group engaged only in technology (design) projects, so their questionnaires evaluated only 6 of the 9 PBLSAT skills.

In their second study they addressed one research question: How do expert PBLSAT teachers evaluate the value of the two support frameworks (PBLSAT workshop and school support)?

Seven expert PBLSAT teachers took part in this study. They attended the PBLSAT workshops (from 21 to $56 \mathrm{~h}$ ) and implemented the program in their schools for 5-7 years. Interviews were conducted with the seven teachers. These interviews were open ended and in-depth (Patton 2002); the questions were about the two PBLSAT support frameworks for teacher professional development: the basic workshop (described in our first study) and the teacher support for their PBLSAT enactment.

From the result it is noticed that all the seven teachers felt that they were respected as teachers and as individuals. They also felt that the workshop staff supported them intellectually in acquiring knowledge and skills, as well as emotionally in dealing with project difficulties.

The teachers in their two studies reported that they (teachers) developed personally and professionally as a result of the two PBLSAT support frameworks. They also reported that this ongoing support motivated them to enact the PBLSAT approach in their classrooms. This was true not only for new teachers, but also for experienced teachers who had taught for many years. They all reported that they experienced a new and special kind of learning experience that they had not experienced in the past.

\subsection{Patricia Melo "Ethical Conflicts in Teaching; The Novice Teacher's Experience" (British, Columbia, 2003).}

The author Patricia Melo (2003) exposes the research problem of his study which was to explore the ethical conflicts and moral dilemmas faced by novice teachers in the Greater Victoria School District (\# 61) in British, Columbia

Forty-eight (48) novice teachers took part in this study and a questionnaire for both close and openended responses were used to gather data. Four major findings from this study indicate that (1) Novice teachers perceive teaching as a moral endeavor, (2) values guide novice teachers in their daily work and novice teachers are comfortable expressing their values in the classroom, (3) the majority of ethical conflicts that novice teachers experience involve students (and not colleagues, administrators or the parents of their students), and (4) the most common philosophical framework that novice teachers use in their ethical decision making is the rule of utilitarian framework.

Now it is perceivable to the novice teachers that teaching is a value- laden profession and they are the moral agent for the society. But sometime they are to be anxious about attributing their values upon their students. On the other hand, to examine the social, cultural and religious influences, it is important for elevating the novice teacher's values. Moreover, teachers have to make a little less stressful for applying their working knowledge and experience of professional ethics and practice. For ethical decision - making, teachers may get assist depending on the philosophical frameworks.

\subsection{S.Mthiyane \& C.Grant Presented a Journal In EMASA Conference "Re-Imagining Novice Teachers as Leaders and the Role they can Play in Building a Community of Educational Leaders/Researchers" (Cape Town-Western Cape, 2011)}

S.Mthiyane \& C.Grant presented a Journal "Re-imagining novice teachers as leaders and the role they can play in building a community of educational leaders/researchers" in EMASA Conference 2011, Cape Town- Western Cape. The aim of their journal was to ascertain what potential student teachers' reflective journals offer for teacher leadership development as well as determine whether they hold any promise for extending, enriching and deepening leadership development programmes for serving educators.

In analysing the students' reflective journals, they employed a multi-layered approach, commencing from a manifest to a more in-depth or latent interrogation of the evidence in the journal. They used 
Hatton and Smith's (1994) framework on the different types of reflective writing as an analytical tool. They identified four levels of reflective writing.

From the data, they found that reflective journals have an important role to play in leadership learning especially for novice teacher leaders. They allow potential leaders to reflect on their teaching and other classroom and school leadership tasks which have a bearing on leadership learning over a period of time.

From their Journal they argued that novice teachers are often an untapped leadership source as they (Novice Teachers) are not viewed as potential agents of change and in order to build a community of educational leaders/researchers, these novice teachers need to be re-imagined as teacher leaders and educated about their valuable change agency role in the schooling context. Furthermore, they viewed that novice teachers will be able to take-up their leadership roles as they embark on a process of action research in their first teaching posts.

\subsection{Helen Meyer "Novice and Expert Teachers' Conception of Learners' Prior knowledge" (2004)}

This qualitative comparative case study by Helen Meyer; focused on the novice and expert teachers' conceptions of the concepts of prior knowledge. This study was conducted on two (02) pre-service teachers, two first-year teachers, and two (02) expert teachers to get the conceptions of learners' prior knowledge. Interviews, Classroom observations and Document analysis procedures were used to gather information about teachers' conceptions. The paramount objective of this study was to know how novice and expert teachers understand the concept of prior knowledge and how they use this knowledge to make instructional decisions. Here the researcher of this study argues, "The process of learning to teach is complex and novices are limited by their lack of background experiences as educators and therefore have limited frameworks for making sense of what is happening in their classrooms". On the other hand, he claims, "When watching expert teachers, their actions and interactions in the classroom seem to be remarkably intuitive, they just know what to do or what to say".

Not with standing, in the finding part of this study, the author recommends that novice teachers hold insufficient conceptions of prior knowledge while expert teachers hold a complex conception of prior knowledge and make use of their students' prior knowledge in significant ways during instruction.

\subsection{Candace Schlein "Exploring Novice Teachers' Experiences with Intercultural Curriculum" (Missouri, 2009).}

In this feature qualitative research article the author intends to investigate the professional development experiences of novice teachers across schools in Japan, Hong Kong, and Canada. The researcher prepared three (3) research questions to establish this study (1) What happens to and within novice Canadian teachers as they practice their profession in schools in Northeast Asia? (2) How do teachers make sense of and adapt to foreign curricula and new cultures of schooling? (3) Does intercultural curriculum development and practice develop educators professionally for situations and interactions in multicultural North American Schools? The researcher conducted the study into the four professional experiences of Canadian novice educators including him. In-depth Interview transcriptions, field notes, Journal entries and Autobiographical response writing were included for collecting all information for this study. As a result, from the findings the author recommended that Experiences with professional practice abroad provide teachers with an embodied and shifting cultural understanding of teachers and students.

\subsection{Janet E. McIntosh "Reader Response Journals in Pre-service Instruction: on Novice Teachers' Reflections their Classroom Implementation" (Northern-Ontario, 2009)}

The objective of this study was to examine novice teachers' reflections on reader response journals for indicating the successful implementation of approaches introduced during pre-service instruction. In a Northern Ontario, five novice pre-service teachers (female) from Faculty of education were the participants for this study. The author, Janet E. McIntosh thinks that interview is an appropriate approach to collect data. So, outside of school hour, the author conducted 50 minutes taped interview with each respondent. It was second half of the school year; because by that time the participants already got the chance to use response journals with their students. The key finding of this research 
study is that Approach used to implement response journals, reference to pre-service course, assessment/evaluation of journals, students "e written journal responses, teachers' role, value of journals, teachers' role, value of journals, journals and examination of self as novice teacher.

\subsection{Susanne Garvis Donna Pendergast "Supporting Novice Teachers of the Arts" (Queens- Land, Australia, 2010)}

This study aimed to provide a snapshot of current perceptions towards support in schools for the arts. The study utilized data from questionnaires with 201 beginning teachers. This paper focuses on supporting novice teachers. A key finding concerns that beginning generalist teachers perceived a general lack of support for the teaching of the arts in their classroom, compared to English and math.

Dianne M. Gut, (Ph.D.), Pamela C. Beam(Ph.D.), Lawrence Burgess, (Ph.D.), Guofang Wan, (Ph.D.) conducted this study named "Developing Professional Competence in Novice Teachers" (Chicago, Illinois, 2010) to present the results of a collaborative engagement between teacher educators, cooperating teachers, and professional interns (student teachers) in inquiry that contributes to scholarship expanding the knowledge base related to teacher education. For their study they selected Five (5) pairs of professional interns and mentor teachers. It is purely qualitative study, so they used (a) Mentor interview protocol, (b) professional intern interview protocol, (c) researcher observation protocol, and (d) instructions for reflective dialog journals. Finally, from the collected data they found that Mentor teachers and professional interns identified several strategies utilized to convey expectations and processes to provide feedback.

\subsection{CHAN Kwok-wai "Teacher Professional Development: In-service Teachers' Motives, Perceptions and Concerns about Teaching” (Hong Kong, 2004)}

To examine the motives, conceptions and concerns of in-service teachers in the process of professional development the researcher Chan Kwok-wai conducted this study in 2004. The respondents were 246 in-service teacher education students of a tertiary institute in Hong Kong. Questionnaire contained 80 items and it was rated on a five-points Likert scale: from 1(Strongly Disagree) to 5 (Strongly Agree). This study identified three motives and two concerns of a sample of in-service teachers in Hong Kong. The three motives were "Intrinsic/Altruistic", "Extrinsic/Job condition"

\subsection{Esmeralda Perez- Gonzalez "A Phenomenological Examination of a Teacher Mentoring Program from the Perspective of Novice Teacher" (Walden University)}

This study focused on how female novice teacher shared their firsthand account of their experiences during their first and second year of teaching. The author invited 25 novice teachers and 10 of them participated in this study. Open-ended surveys, face to face interviews and observation approach were used for gathering the data. The objective of this study was to identify the perceptions the novice teachers have towards the district's teacher mentoring Program, to identify the impact a mentoring program has on teacher development, to determine what worked well, what areas may need refinement, and what changes may need to be made to impact future novice teachers. The findings emerged from the collected data of this purely qualitative doctoral research were- mentoring academies, professional development for both mentors and mentees, and campus support, cultivating collegial relationships, trusting partnerships, communication practices and meaningful dialogue, Positive influences, program modifications, professional and supportive connections. The researcher claimed, "The study findings may bring about positive social change for the participating school district, the mentoring program being implemented first- and second-year novice teachers and the teaching profession.

\section{CONCLUSION}

For knowing an overview of the main ideas and findings about the professional development of novice teachers, each article has been criticized briefly. The paramount objective of this article review is to explore the characteristics and factors which are essential for novice teacher professional development. Training program and mentoring program are the good opportunities for a novice teacher to achieve his/her professional development. These programs may be defined as learning process. Novice teachers need to acquire some skills and knowledge 'in order to become effective promoters of their professional development' (Eleonora Villages-Rimers, 2003). Novice teachers need 
time and support as Moor (2000) suggests "plan ahead, start early, establish a routine, tape internal resources, establish a mentoring program, hold meetings" for professional development. So, "there should be multiple strategic sites for professional growth within the education-policy system: district, department, school and professional organization. Each of these can make a particular contribution that may take different forms and involve various strategies, but all are equally as important" (McLaughlin, 1994).

\section{REFERENCES}

[1] Abel, M.H. \& Sewell, J. (1999). Stress and burnout in rural and urban secondary school teachers. The Journal of Educational Research. 92(5), 287-300.

[2] Adams, E. (2001). A proposed causal model of vocational teacher stress. Journal of Education and Training, 53(2), 223-245.

[3] Admiraal, W.F., Korthagen, F.A.J., \& Wubbels, T. (2000). Effects of student-teachers' coping behaviour. British Journal of Educational Psychology, 70, 33-52.

[4] Anderson, G. (1991). Cognitive Politics of Principals and Teachers. In J. Blasé (Ed.), The Politics of Life in Schools: Power, Conflict and Cooperation (pp.120-138). Newbury Park: Sage Publications

[5] Bandura, A. (1997). Self-efficacy: The exercise of control. New York: W.H. Freeman.

[6] Bullough, R.V., Jr. (1989). First year teacher: A case study. New York: Teachers College Press.

[7] Black, R. S., \& Langone, J. (2004). Social awareness and transition to employment for adolescents with mental retardation. Remedial and Special Education, 18(5), 214-222.

[8] Briggs, R.P., McCurdy, W.J. (1978). Marine fishes taken in waters of the North Coast of Ireland during 1977. Irish Naturalists' Journal, 19:267-268

[9] Calderhead, J.; Shorrock, S. B. (1997). Understanding teacher education: case studies in the professional development of beginning teachers. London: The Falmer Press.

[10] Eleonora Villages-Rimers (2003): Teacher Professional development (an international review of literature).

[11] McLaughlin, M.W.(1994) "Strategic sites for teachers' professional development". In Grimmett, P.P.; Neufeld, J. (Ed), teacher development and the struggle for authenticity; Professional growth and restructuring in the context of change. New York: Teachers College Press.

[12] Moor, K.B. (2000): "Successful and effective professional development" In Early Childhood Today, 15(3), $14-15$.

\section{AUTHORS' BIOGRAPHY}

Hasina Banu Shirin, She holds $\mathrm{PhD}$ in Education from the International Islamic University Malaysia, Master of arts in English, Bachelor of Arts (Hons.) in English and Post-graduate Diploma in Library \& Information Science (achieved gold award) from the National University of Bangladesh.

Abrar Yahya Khawaji, Currently she is pursuing her $\mathrm{PhD}$ in Education in the International Islamic University Malaysia.

Citation: Hasina Banu Shirin, Abrar Yahya Khawaji. "Novice Teachers' Professional Development: A Meta-Analysis". International Journal of History and Cultural Studies (IJHCS). vol 4, no. 4, 2018, pp. 51-56. doi: DOI: http://dx.doi.org/ 10.20431/2454-7654.0404002.

Copyright: () 2018 Authors. This is an open-access article distributed under the terms of the Creative Commons Attribution License, which permits unrestricted use, distribution, and reproduction in any medium, provided the original author and source are credited. 